\title{
2 I 24 Whole-Heart Magnetic Resonance Coronary Angiography (WH MRCA) with visual feedback
}

\author{
Shigehide Kuhara*1, Tomohisa Okada², Shotaro Kanao², Ayako Ninomiya1, \\ Saori Sato1, Toshikazu Kamae ${ }^{2}$, Kimio Goto ${ }^{2}$ and Kaori Togashi ${ }^{2}$
}

Address: ${ }^{1}$ Toshiba Medical Systems Corporation, Otawara-shi, Japan and ${ }^{2}$ Department of Diagnostic Radiology, Kyoto University, Kyoto, Japan * Corresponding author

from I th Annual SCMR Scientific Sessions

Los Angeles, CA, USA. I-3 February 2008

Published: 22 October 2008

Journal of Cardiovascular Magnetic Resonance 2008, I0(Suppl I):A393 doi:I0.I I86/I532-429X-10-SI-A393

This abstract is available from: http://jcmr-online.com/content/I0/SI/A393

(C) 2008 Kuhara et al; licensee BioMed Central Ltd.

\section{Introduction}

Currently, WH MRCA studies are usually performed during free breathing while monitoring the position of the diaphragm. However, since the scan time is rather long, the patient's breathing pattern may change during scanning, and scanning sometimes cannot be completed. In another method, WH MRCA is performed during multiple breath-holds. However, patients cannot hold their breath within a threshold each time, and it is also difficult to perform scans in a short time. These problems are attributable to the fact that patients cannot recognize their breathing level and therefore cannot adjust it.

\section{Purpose}

We have developed a visual feedback (VFB) system for visually displaying the breathing level to the patient, thus permitting the patient to adjust his or her breathing level. The present study was undertaken to investigate the usefulness of the VFB system in WH MRCA studies.

\section{Methods}

All studies were performed using a 1.5-T MRI scanner with a whole-body phased-array coil system and 16-channel receivers. A 3D SSFP pulse sequence was used in combination with Real-time Motion Correction (RMC), which detects the position of the diaphragm and performs correction to compensate for the effects of respiratory motion. Scanning was performed with TR/TE $=4.3 / 2.2$, matrix size $=192 \times 256$, and number of segments $=4$. The parallel imaging factor was 2 in the phase direction and
1.5 in the slice direction. A total of 80 slices were obtained. The spatial resolution was $0.75 \times 0.75 \times 0.75$ $\mathrm{mm} 3$. An abdominal band was used, but set looser than usual for abdominal band-free scanning.

In the VFB system, information concerning the breathing level is obtained by an RMC probing pulse, converted to a video signal, and projected onto a screen in front of the scanner by an LC projector. The displayed information is reflected in a mirror, allowing it to be viewed by the patient. Eleven healthy volunteers were scanned using the following three methods and the results were compared: 1) WH MRCA during free breathing (FB-VFB), 2) $\mathrm{WH}$ MRCA during free breathing with VFB (FB+VFB), and 3) Single Slab Multi-breath-hold WH MRCA with VFB (BH+VFB). Figure 1.

The MRCA quality was assessed by two radiologists for each segment using grades 0-4 (3: visualized and adequate for diagnosis, 1: visualized but inadequate for diagnosis).

\section{Results}

Although scanning was not completed in 2 cases in method 1 due to changes in breathing level and a scan time longer than $20 \mathrm{~min}$, all scans were completed in methods 2 and 3 . The scan times were reduced in 7 cases $(64 \%)$ in method 2 as compared with method 1. However, the average scan times were almost identical $(9.99 \pm$ $2.24 \mathrm{~min}$ for method 1 and $9.98 \pm 2.50 \mathrm{~min}$ for method 


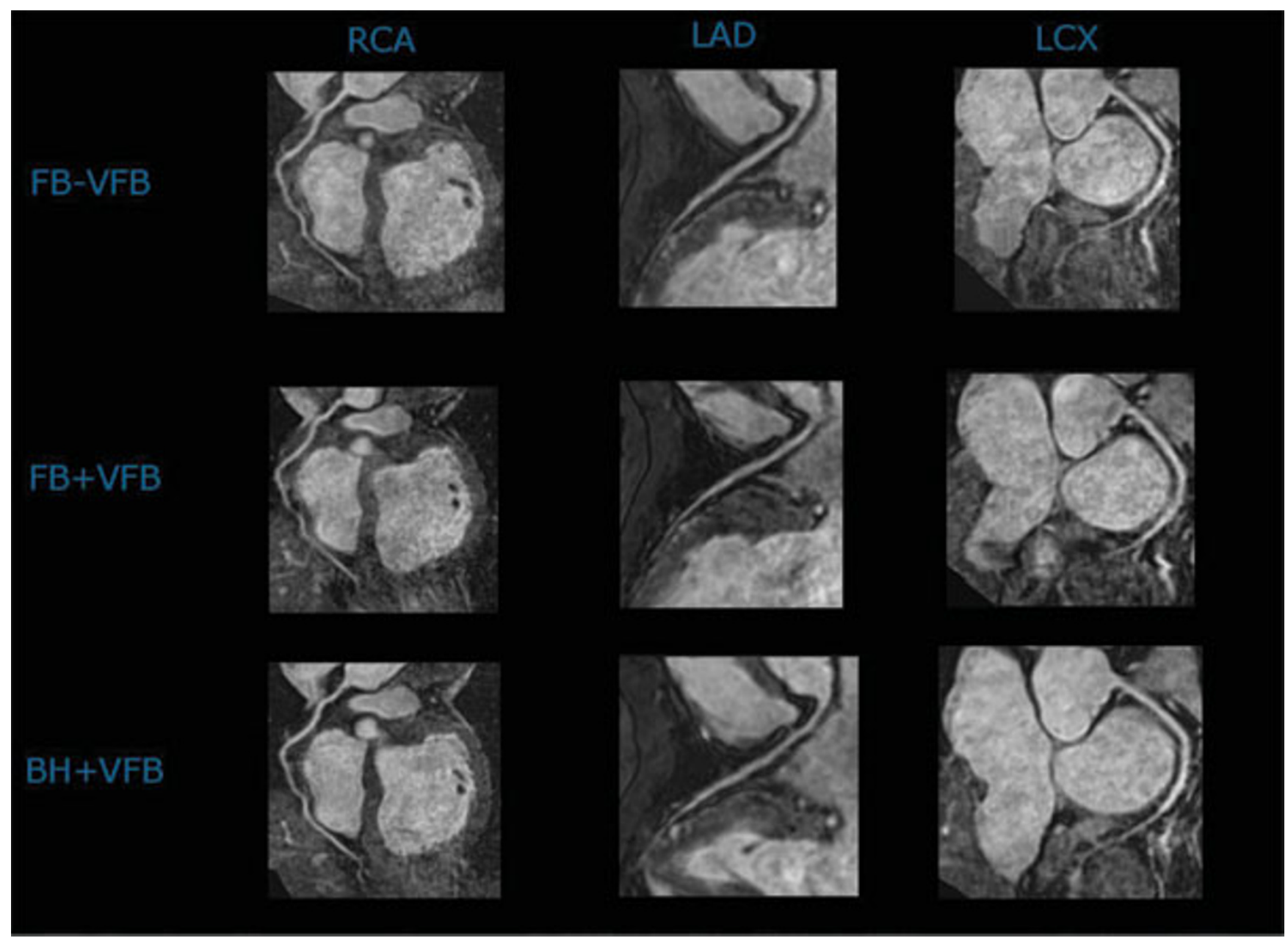

Figure I

Comparison of FB-VFB, FB +VGB and $\mathrm{BH}+\mathrm{VFB}$.

2 ). This was due to 4 cases (36\%) with rather long scan times in which controlling the breathing level was difficult due to the rather long feedback time constant.

The average scan time was significantly reduced in method $3(8.16 \pm 1.28 \mathrm{~min})$. In this method, the long feedback time constant was not so much of a problem because the breathing level was constant during breathholding and was easily recognized and corrected. There were no significant differences in average scores between methods 1 and $3(0.195, \mathrm{P}=0.161)$, although there was a slight reduction in method 2 as compared with method 1 (0.316, $\mathrm{P}=0.027)$. These findings suggest that multibreath-hold scanning with VFB provides the best image quality in the shortest practical time.

\section{Conclusion}

Using the VFB system, WH MRCA can be performed without difficulty or prolongation of the scan time, especially in multi-breath-hold WH MRCA in a shorter time. It is therefore concluded that the VFB system can be helpful in WH MRCA studies.

Publish with BioMed Central and every scientist can read your work free of charge

"BioMed Central will be the most significant development for disseminating the results of biomedical research in our lifetime. "

Sir Paul Nurse, Cancer Research UK

Your research papers will be:

- available free of charge to the entire biomedical community

- peer reviewed and published immediately upon acceptance

- cited in PubMed and archived on PubMed Central

- yours - you keep the copyright

Submit your manuscript here:

http://www.biomedcentral.com/info/publishing_adv.asp
BioMedcentral 